\title{
Underground oil shale mine surveying using handheld mobile laser scanners
}

\author{
Kaia Kütimets $^{(\mathrm{a})}$, Artu Ellmann ${ }^{(\mathrm{a}) *}$, Erik Väli ${ }^{(\mathrm{b})}$, Sander Kanter ${ }^{(\mathrm{b})}$
}

(a) Department of Civil Engineering and Architecture, School of Engineering, Tallinn University of Technology, Ehitajate tee 5, 19086 Tallinn, Estonia

(b) Department of Geology, School of Science, Tallinn University of Technology, Ehitajate tee 5, 19086 Tallinn, Estonia

Received 21 August 2020, accepted 25 January 2021, available online 10 March 2021

\begin{abstract}
The applicability of a handheld mobile laser scanner (MLS) in oil shale mine surveys and subsequent three-dimensional modelling of postextracted surfaces is assessed. Recommendations for optimizing the acquisition and processing of MLS data and visualization of the results are given. The resulting surface geometry accuracy is validated via terrestrial laser scanner (TLS) reference data. Typical discrepancies between TLS and MLS data points remain within 2 and $5 \mathrm{~cm}$ in horizontal and vertical directions, respectively. The area of pillars and volumes of the extracted material are estimated by data analysis. The results are compared with those of the conventional mining survey. The detected discrepancies evidence that the laser scanning results provide a realistic outcome due to the evenly and densely spaced points within the point cloud. The result discrepancies between the tested surveying technologies are small and fully satisfy contemporary accuracy requirements. However, the handheld mobile laser scanning appears to be the most suitable method for underground mining surveys. The survey results enable reduction of mining losses and improvementt of the design of mining geometry.
\end{abstract}

Keywords: mobile laser scanning, handheld laser scanner, SLAM algorithm, mining losses, underground mine, Estonia.

\section{Introduction}

Underground oil shale mining is a labour-intensive and challenging industry. Precise mine surveys are required to ensure the productivity and work safety of the mining processes as well as due consideration of accompanying environmental issues. Accordingly, the tasks of the mine surveying engineers

\footnotetext{
* Corresponding author: e-mailartu.ellmann@ttu.ee
}

(C) 2021 Authors. This is an Open Access article distributed under the terms and conditions of the Creative Commons Attribution-NonCommercial 4.0 International License (http://creativecommons.org/licenses/by-nc/4.0/). 
include staking out the designed mining project and conducting post-extraction surveys, i.e. performing calculations and accurately marking the direction of working face, determining the extracted volumes, mapping the locations and volumes of underground supportive structures (pillars). During the surveys also the run-of-mine quality is estimated, e.g. by measuring the thickness of the oil shale seam. The mining survey results are used for estimating and reducing the mining losses. Specified rock pressure estimates enable one to further improve the design of mining geometry. At the occurrence of unexpected events, e.g. land subsidence, pillar failures, room collapse or mine roof droppings, the survey data are often reanalysed. A variety of classic geodetic instruments, such as total stations or levelling instruments, are used for mine surveys. Traditional pointwise surveys are not too complicated yet time-consuming and laborious. In addition, the pointwise measurements may yield omission errors due to surface unevenness between sequential survey points [1]. Hence, one may need economically viable alternative methods for semi-automatic mine surveys.

The development of surveying technologies over the past decade has led to new data acquisition methods that afford high-resolution, fast and accurate surveys. In particular, laser scanning is a relatively novel and rapidly developing surveying method, which is especially useful for reconstructing the geometry of surfaces by generating coordinated point clouds or three-dimensional (3D) surface models. Laser scanning enables an automated data capture of the surrounding environment by measuring a countless number (millions) of survey points within a short period of time. The laser surveying is contactless, therefore there is no danger of damaging the object and a surveyor's work hazards are reduced as well. Note that mines contain potentially dangerous areas due to exposed hazardous materials, machinery in operation and roof droppings.

Laser scanners can be mounted on the tripod (terrestrial laser scanning, TLS) and also on moving platforms (mobile laser scanning, MLS). Nowadays, usage of TLS is quite common for a variety of civil engineering applications, including for example as-built surveys and deformation monitoring (see, e.g., [2-5]), and also for different technical infrastructure (roads, tunnels, bridges) surveys [6-9]. Today the static TLS has become a standard tool in geodesy that enables achieving sub-centimetre accuracy of the survey points. Therefore, the standard TLS survey results can be utilized for assessing the results of alternative and emerging surveying technologies.

Conversely, in mobile laser scanning the instrument is attached to the moving platform, whereas the trajectory of the vehicle has to be determined in conjunction with Global Navigation Satellite System (GNSS) and Inertial Measurement Unit (IMU) datasets. These standard vehicle mounted mobile mapping systems are primarily designed for outdoors, whereas their utilization in indoor conditions remains a challenge. The MLS are widely used for mapping of transport corridors, whereas a typical accuracy is rarely better 
than $5 \mathrm{~cm}$ [7]. Intuitively, mine surveying can also benefit from the mobile laser scanning surveys, see a study by Zlot and Bosse [10]. The researchers' experiments in copper and gold mines demonstrated the superiority of MLS over traditional pointwise geodetic measurements.

The prices of the novel surveying equipment have significantly lowered over the past decade. The above factors have led to a widespread implementation of new instruments and methods in many economic sectors within the past few years. Modern contactless surveying technologies are expected to alter the specificity of underground mine surveys in a way they have altered the entire surveying community. Also the mining companies have innovatively started to encourage the usage of laser scanners for mine surveys. For instance, in Estonia a state-owned energy enterprise Eesti Energia has requested researchbased advice on implementation of modern surveying technology for oil shale mining industry [11]. Note that deficiencies in estimating the oil shale volumes in Estonia were addressed already in 2003 by Koitmets et al. [12].

To the best of our knowledge, there is no study focusing on the usage of handheld MLS in underground mine industry surveys as yet. Hence, the aim of the present study is to assess the applicability of handheld MLS in mine surveys and subsequent 3D modelling of post-extracted surfaces, as well as in estimating mining losses. The achieved surface geometry accuracy is validated via TLS acquired reference data, which also allows identification of possible discrepancies in the experimental surveying results.

The outline of the paper is as follows. The Introduction is followed by a review on relevant background principles of the study and considerations on the applicability of the laser scanning technology in oil shale mine surveys in Estonia. The third chapter introduces instruments and software used in the study, as well as the procedure of data acquisition. The next chapter reviews data processing and assessment of the results. A brief summary concludes the paper.

\section{Background principles}

\subsection{Review on surveying conditions and constraints in underground oil shale mining}

The Estonian oil shale mining industry uses two mining methods - underground mining and opencast strip mining. The main method for underground mining is the room and pillar method that implies precisely directed drillings. The carefully dosed blastings form mining rooms, the roofs of which are supported by pillars. The oil shale deposit in Northeast Estonia is located at a depth of 20-70 m, the mean overburden thickness is $31 \mathrm{~m}$, see Figure 1. 


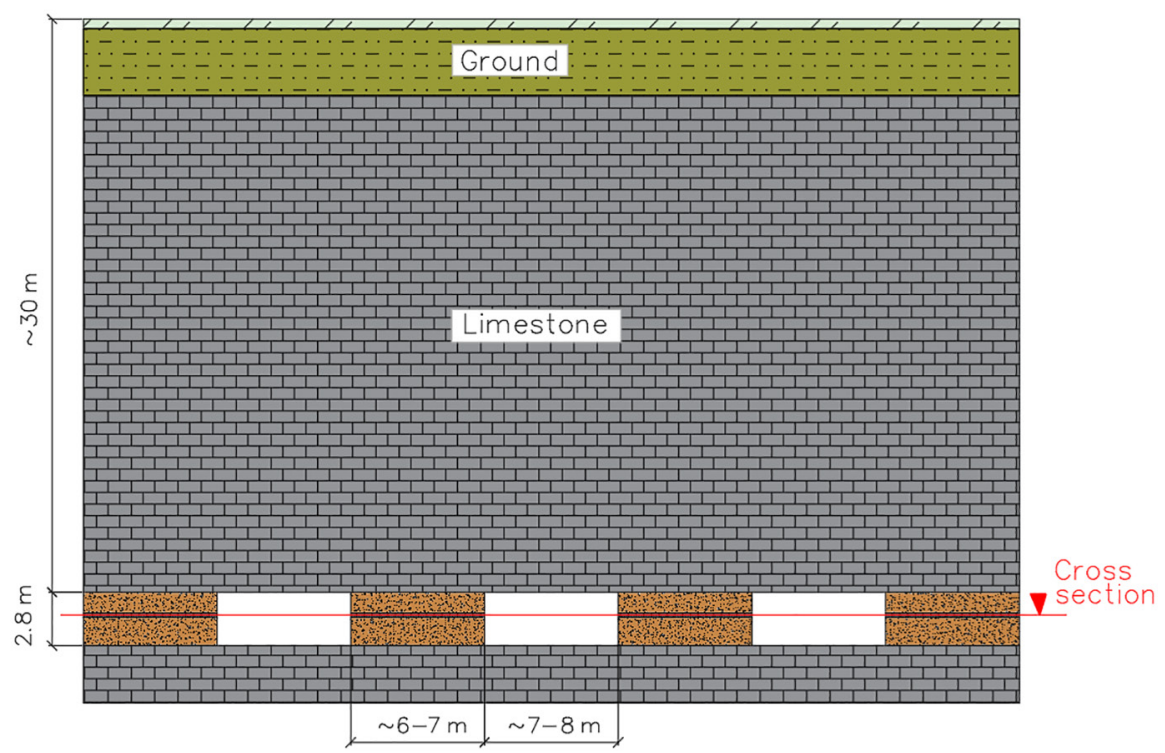

Fig. 1. Vertical intersection of the mining rooms (denoted by white voids) and cuboid shaped pillars (the brown coloured texture) (modified from [13]). Note the limestone interbed that coincides with the horizontal cross section (the red line denoted), as discussed in Chapter 4.

The thickness of the oil shale seam (denoted in literature by A-F1; contains also a few limestone interlayers) varies between 2.7 and $2.9 \mathrm{~m}$, hence, also the vertical distance from the room floor to the roof is mostly $2.8 \mathrm{~m}$. Due to the machinery used, such as Load Haul Dump (LHD) loaders, development and rock support drill rigs, some mine roofs, e.g. those above the conveyer belts, are elevated up to $3.8 \mathrm{~m}$, though.

One of the major constraints in implementing any surveying equipment/ method is that the mine surveyor's tasks include setting out directions for somewhat obsolete (at the level of Industry 2.0) mining/drilling equipment and machinery. Such machines possess neither modern self-navigation nor machine guidance options, therefore the drilling locations and directions need to be determined manually. For aiding this procedure the survey traverse points are conventionally mounted on the mine roof. These points are usually aligned (with the interval of ca $15 \mathrm{~m}$ ) along the middle axis of certain chains of mining rooms, see Figure 4 for an illustration. The coordinates of survey traverse points are determined by total stations using conventional angle and distance measurements.

The annual oil shale extraction by both underground and opencast mining in Estonia is about 15 mill tons, whereas the mining losses comprise 4 mill tons. The main prerequisites for increasing the efficiency of oil shale mining 
is the reduction of losses occurring in underground mining. The average loss in the Estonian underground oil shale mines is about 29\%. These occur mainly due to the pillars left to support the mining roof, whereas the volumes of the pillars depend directly on the mine overburden thickness. Hence, the precise estimation of the locations and volumes of the pillars is very essential for increasing the efficiency of oil shale mining.

The locations of pillars are surveyed by handheld single-point Disto-type laser distance meters with respect to the roof mounted survey control network points. The extracted volumes and sizes of pillars are calculated with simplified length*width*height formulas. This kind of method is fast and according to the present study results (see Chapter 4) also reasonably accurate, although it does not take into consideration the disproportions of mine pillars, roofs and floors. The final "as-extracted" drawing plans are compiled in CAD-type CREDO computer programs [14]. Such stakeout and volume surveys are conducted routinely at different stages of underground works. Accessibility is also an issue for mining surveyors as teams often have only a short amount of time available to get all of the relevant underground measurements done.

\subsection{Aim of the study}

The mine surveys are strictly law regulated activities in Estonia. A special governmental decree [15] sets requirements, procedures and standards for the mine engineering surveys and the resulting reporting. The aforementioned regulation is conservatively leaning towards utilisation of conventional surveying methods in underground mines. Hence, current novel data acquisition techniques, e.g. laser scanning, are not listed amongst allowable mine surveying technologies. The mining industry has traditionally been wary of adopting new technologies, however, recent years have demonstrated benefits of using robots, drones, and new ways of progress reporting in other engineering branches. Accordingly, this study intends to examine the applicability of modern data acquisition technologies in underground oil shale mines. Thus, various new technologies for spatial data acquisition in an oil shale mine are studied for improving and complementing the presently used methods. However, the early-development-stage technologies were excluded from the current study due to their highly research-intensive implementation and complexity of usage.

It is thus assumed that the routine data acquisition and processing need to be conducted by a qualified mine surveyor rather than the highly-skilled academic personnel. These intentions suggest seeking for commercially available equipment and software which also have vendor support and training. One of the research aims is advising on automatization of mine surveys as much as possible. In the selection of technologies focus is on the practical application of existing measuring technologies in real mine 
surveying situations. For this, contemporary mine surveying methods and technologies were first documented by interviewing the mine surveyors and during in situ observations. Thereafter, technologies suitable for oil shale mine surveying were identified and field-tested. For instance, also the application of the drone technology in underground mine surveys was initially considered. However, the photo camera-equipped unmanned aerial vehicle (UAV) appeared to be nonpractical in low roof mines. In addition, the rather dark underground conditions would not allow conducting photogrammetric surveys. The prices of drone mountable laser scanner systems were estimated to be disproportionally high, considering the goals of the present study and also the prices of alternative data acquisition technologies.

After the tests it was concluded that laser scanning is the most optimum solution, satisfying the existing conditions and constraints (see Subchapter 2.1). The method enables conducting cost-effective, productive and accurate measurements, as well as carrying out comprehensive analyses of the results. Accordingly, this contribution focuses on the implementation of laser scanning technology in post-extraction mine surveys. Therefore, the following subchapter reviews the principles of the adopted technology.

\subsection{Principles and advantages of laser scanning surveys}

Laser scanners are equipped with a Light Detection and Range (Lidar) sensor that is sending light pulses to the object and receives their back reflections. The travelling time of the reflected laser pulse enables determination of the distance between the sensor and the object. The user interface of TLS instruments has become easy to handle and is rather similar to that of traditional geodetic instruments the surveyors are accustomed to. Beneficial to mining surveys, the Lidar technology does not require bright light conditions, unlike surveys using optical instruments.

Due to the technological developments over the past decade the TLS data acquisition rates have increased up to $1 \mathrm{MHz}$. The panoramic field of view can be up to $360^{\circ}$ (a full circle) in the horizontal and $300^{\circ}$ in the vertical direction, thus leaving only a small area under the scanner unsurveyed. All the reflections within the instrument's field of view and maximum surveying range are recorded and then used for reconstructing the surrounding surfaces. Each TLS survey point in the resulting point cloud can be characterized by the coordinate components, i.e. the $3 \mathrm{D}$ position (rectangular $\mathrm{x}, \mathrm{y}$ and $\mathrm{z}$ coordinates) of the point. In general, TLS survey results are referred to the instrument's internal coordinate system or an external coordinate system (e.g. a local coordinate system). Multiple scanning stations are usually needed for complex-shaped structures. To obtain a complete representation of the scanned object, the data from different scanning stations need to be referred to a common coordinate system. For this the survey control network points are 
made identifiable for the scanning. The survey data are transformed into the requested coordinate system (also known as registration or georeferencing) during the data processing stage.

In this study, the tripod mounted TLS surveys were initially considered to be a feasible approach for post-extraction surveys. This was underground tested, but moving the bulky surveying equipment became quickly ineffective, especially when compared to an alternative technology. Indeed, a more appealing and time-efficient approach appeared to be using handheld mobile laser scanning that is based on the innovative simultaneous localization and mapping (SLAM) technology.

The SLAM algorithm is devised for a simultaneous calculation of the laser scanner trajectory and the point cloud of the surrounding surfaces. The inertial measurement unit (IMU) determines the spatial movements of the surveying device. One sweep of the spinning 2D sensor is needed for scanning the field of sight. The next sweep yields the initial trajectory and scans from a different viewpoint. Sequential sweeps are used to match the point clouds together, and correct and smooth the trajectory. This process is continuously repeated, whereas every new iteration perfects the surrounding geometry and corrects the device's location. Correspondingly, the point cloud quality improves and increases spatially by adding new surveying sections. Advantageously, no GNSS signal is needed for trajectory determination, thus the SLAM approach is applicable in mines.

The SLAM algorithm exploiting a mobile laser scanner was developed by Zlot and Bosse $[10,16]$. The laser scanning was conducted for $17 \mathrm{~km}$ route survey in copper and gold mines. The SLAM device equipped platform was driven at mine traffic speed, instead of the previously used stop-and-go method. The spatial data acquisition used a fully automated workflow. The results obtained, which appeared to be satisfactory for accurate mapping and point cloud generation, were then used for planning large-size mining equipment transportation.

Accordingly, this study focuses on the implementation of the SLAM algorithm based handheld mobile laser scanning technology in underground surveys in oil shale mines. For this purpose, a commercially manufactured handheld MLS device was tested. The focus was on the device's applicability in underground mine surveys, capability of shortening the surveying time, simplicity of handling, data processing efficiency and the reachable accuracy as well. The TLS cm range accuracy survey results are used for verification of the handheld scanning results. 


\section{Mine survey case study}

\subsection{Instruments used}

Two commercially manufactured laser scanners were tested: a tripod mounted terrestrial laser scanner for acquiring reference data and a handheld mobile laser scanner for obtaining mine survey data. For the technical specifications of the devices see Table 1.

Table 1. Technical specifications of the laser scanners used

\begin{tabular}{|c|c|c|}
\hline Characteristics & $\begin{array}{l}\text { Handheld mobile laser } \\
\text { scanner }\end{array}$ & $\begin{array}{c}\text { Tripod mounted terrestrial } \\
\text { laser scanner }\end{array}$ \\
\hline Model and reference & $\begin{array}{c}\text { GeoSLAM ZEB-REVO } \\
{[17]}\end{array}$ & $\begin{array}{c}\text { Faro Focus } \\
\text { [18] }\end{array}$ \\
\hline Maximum range & $\begin{array}{l}\text { Up to } 30 \mathrm{~m} \text { in optimal } \\
\text { conditions, } \\
\text { usually } 15 \text { to } 20 \mathrm{~m}\end{array}$ & 0.6 to $330 \mathrm{~m}$ \\
\hline $\begin{array}{c}\text { Field of view (vertical/ } \\
\text { horizontal) }\end{array}$ & $270^{\circ} / 360^{\circ}$ & $300^{\circ} / 360^{\circ}$ \\
\hline Measurement speed & $\begin{array}{l}100 \text { line } \mathrm{p} / \mathrm{s} \\
43200 \mathrm{p} / \mathrm{s}\end{array}$ & $976000 \mathrm{p} / \mathrm{s}$ \\
\hline $\begin{array}{c}\text { Scan range noise, ranging } \\
\text { error }\end{array}$ & $\pm 30 \mathrm{~mm}$ & $\pm 2 \mathrm{~mm}$ \\
\hline Laser safety classification & Laser Class 1 & Laser Class 1 \\
\hline Laser wavelength & $905 \mathrm{~nm}$ & $1550 \mathrm{~nm}$ \\
\hline Operating conditions & $\begin{array}{c}\text { Temperature } 0 \text { to } 50{ }^{\circ} \mathrm{C} \\
\text { Humidity }<85 \% \mathrm{RH}\end{array}$ & Temperature 5 to $40^{\circ} \mathrm{C}$ \\
\hline Weight & $\begin{array}{l}\text { Scanning head } 1 \mathrm{~kg} \text {, carry } \\
\text { case and contents } 4.1 \mathrm{~kg}\end{array}$ & $5.2 \mathrm{~kg}$ \\
\hline Dimensions & $\begin{array}{c}\text { Scanning head } \\
80 \times 113 \times 140 \mathrm{~mm}\end{array}$ & $240 \times 200 \times 100 \mathrm{~mm}$ \\
\hline Battery endurance & Approximately $4 \mathrm{~h}$ & $4.5 \mathrm{~h}$ \\
\hline
\end{tabular}




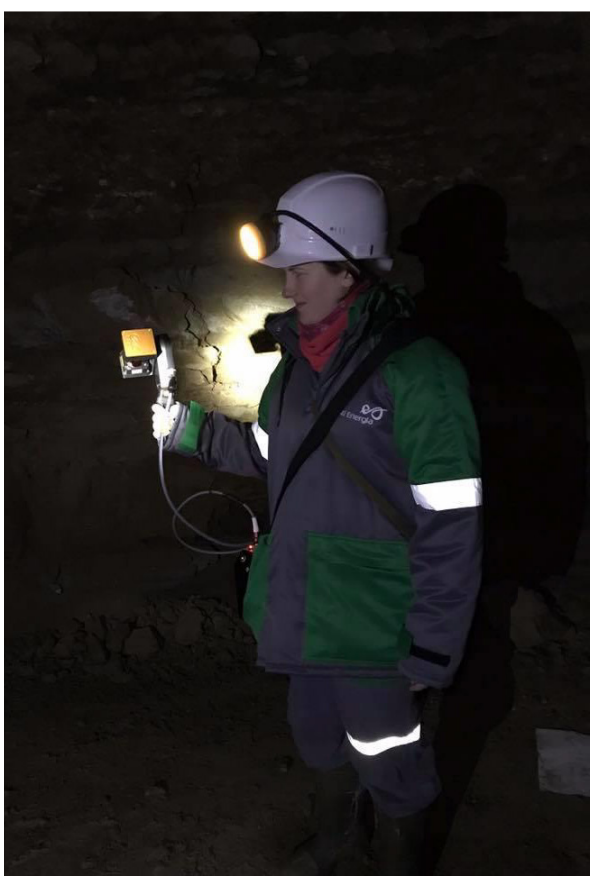

Fig. 2. The handheld laser scanner GeoSLAM ZEB-REVO in the oil shale mine.

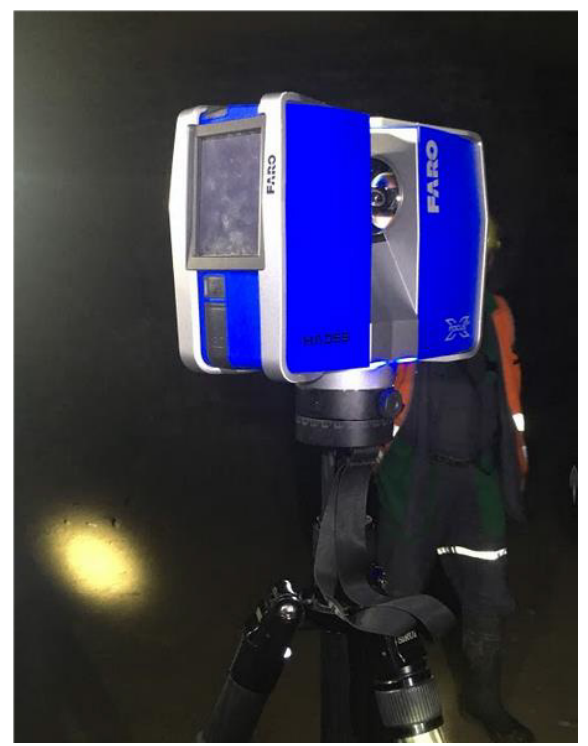

Fig. 3. The tripod mounted terrestial laser scanner Faro Focus used for aquiring the reference data for the oil shale mine survey.

The GeoSLAM manufactured instrument ZEB-REVO (Fig. 2) is based on the SLAM algorithm that takes 2D laser scanning and IMU data sets and connects them to the 3D point cloud $[10,16]$. The used handheld MLS operates in the "walk-and-scan" method of data collection, capturing 42000 points per second, within a range of 30 meters. Detailed instructions on the device usage can be found in [17].

The tripod mounted terrestrial laser scanner (the used model Faro Focus ${ }^{3 \mathrm{D}}$ X330 is shown in Fig. 3) is applied for the accurate and high-resolution surveying of selected mine rooms. Such a scanner is widely utilised for an accurate surveying of various civil engineering objects, its data acquisition and processing routines are already standardized. Thus this scanner type is suitable for constructing the reference data for the handheld MLS based mine surveys.

\subsection{Survey area}

Two different mining blocks (no 1214 and no 1707, the former is shown in Fig. 4) of the Estonia underground oil shale mine, which is located in Northeast Estonia, were surveyed within the frames of the present study. 


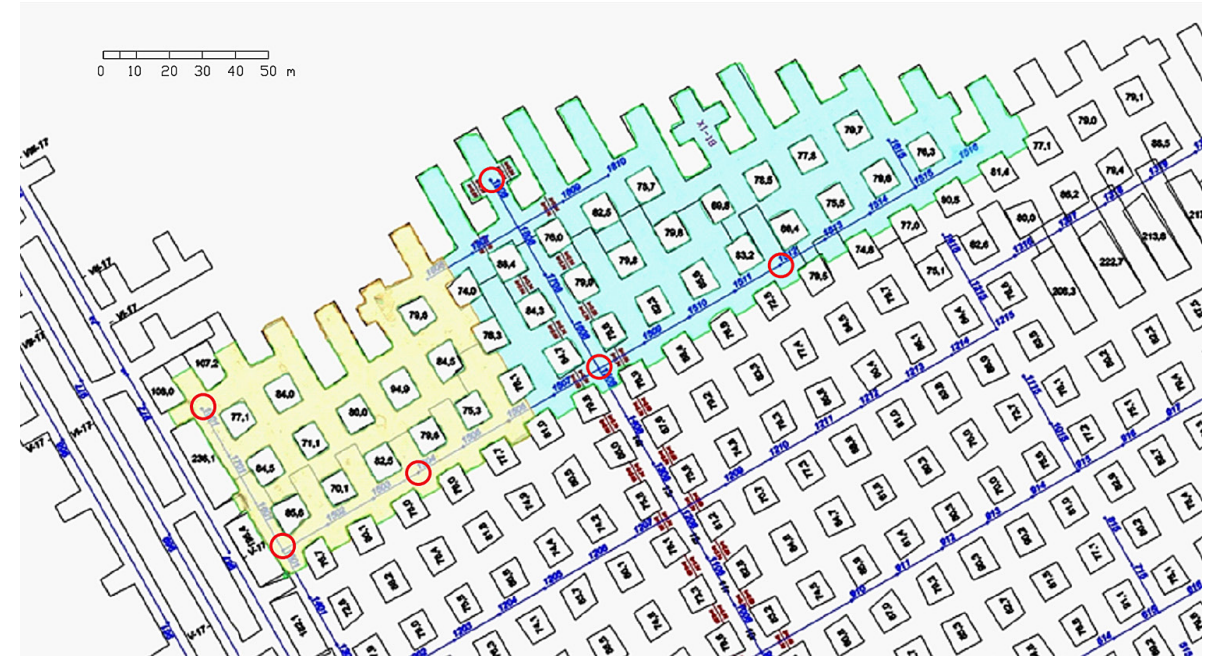

Fig. 4. The configuration of the surveyed mining block no 1214. The yellow area is the control area that is measured with both the TLS and handheld MLS, whereas the blue area is measured with the handheld MLS only. The line-connected dark blue and grey marks denote mining survey network points. The used spherical scanning targets are marked as red circles, the quadrilaterals denote locations of pillars. The underlying map is compiled by the surveyors of the Estonia oil shale mine.

The TLS scanned control area (yellow) comprises approximately $5200 \mathrm{~m}^{2}$ and contains 23 scanning stations. Reference data were collected using the "stop, scan and go" method. The TLS stations were chosen to position at the intersections of the underground drifts. The entire TLS survey consumed altogether 1.5 hours, hence every station survey took about 4 minutes. Simultaneously the handheld MLS device was foot walked (accompanied with continuous sweep-like hand movements) within the mining block. Ca $14500 \mathrm{~m}^{2}$ (the same control area and adjacent mining rooms, i.e. comprising both yellow and blue areas in Fig. 4) was scanned by a handheld laser scanner within $40 \mathrm{~min}$. Hence an area almost three times as large was measured in half the time by using the handheld MLS device. Surveys in the other similar mining block (no 1707) were conducted likewise. Affording similar conclusions and results (not discussed in detail in this contribution), the above surveys allow further generalizations and support the proposed MLS surveying methodology.

\subsection{Georeferencing the laser scanning point clouds}

A conventional survey control network had already been constructed by the mining surveyors on the mine roof (see Fig. 4 where line-connected dark blue and grey marks denote locations of coordinated points). For the 

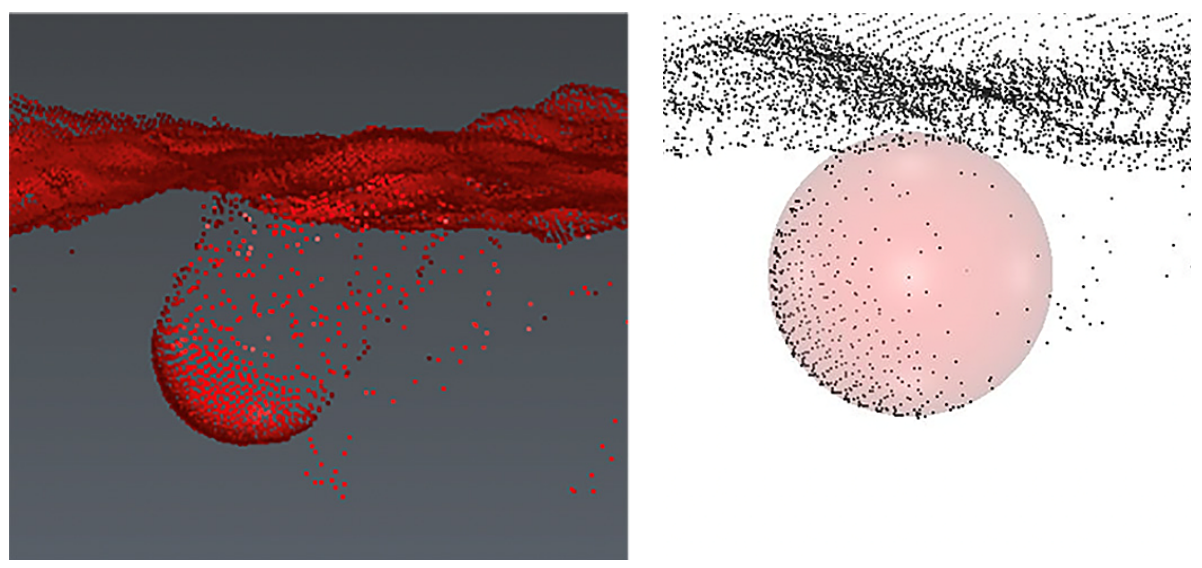

Fig. 5. The laser scanner data embedding the spherical target (the left hand side), the corresponding virtual target (a sphere with $\varnothing 65 \mathrm{~mm}$ ) as incorporated into the point cloud (the right hand side).

point cloud registration of a continuous survey minimum three coordinated targets are needed. Therefore the spherical targets $(\varnothing 65 \mathrm{~mm})$ were attached to six randomly selected control points, for their locations see Figure 4 . The approximate shapes of these targets were later, in the data processing stage, identified in point clouds and then replaced by virtual targets with equivalent parameters, i.e. $\varnothing 65 \mathrm{~mm}$ spheres (Fig. 5).

The coordinates and heights of the target centre can be precisely derived, hence the post-survey georeferencing converts the different point clouds into a common point cloud.

\subsection{Handheld MLS surveying routes}

It is advisable to start and finish the handheld SLAM survey route at the same location $[10,19]$, which also coincides with the spherical target (see a large red circle in Fig. 6). For the route orienteering purposes occasionally circling around the scanning targets is required, see Figure 6.

The scanned point cloud density also shows the measuring range limitations of the SLAM device used, the farther away from the trajectory the less dense the point cloud, see Figure 6. The trajectory jerkiness is due to hand-made sweeping movements. Note the irregular shapes of pillars, as opposed to computer-drawn straight-line shapes in Figure 4. It is recommendable to revisit the surveyed surfaces from a different angle, this improves the consistency of the trajectory and the MLS point cloud. For achieving the best result all advices on and recommendations for scanning with a handheld laser scanner should be followed, see [17] and [19]. 


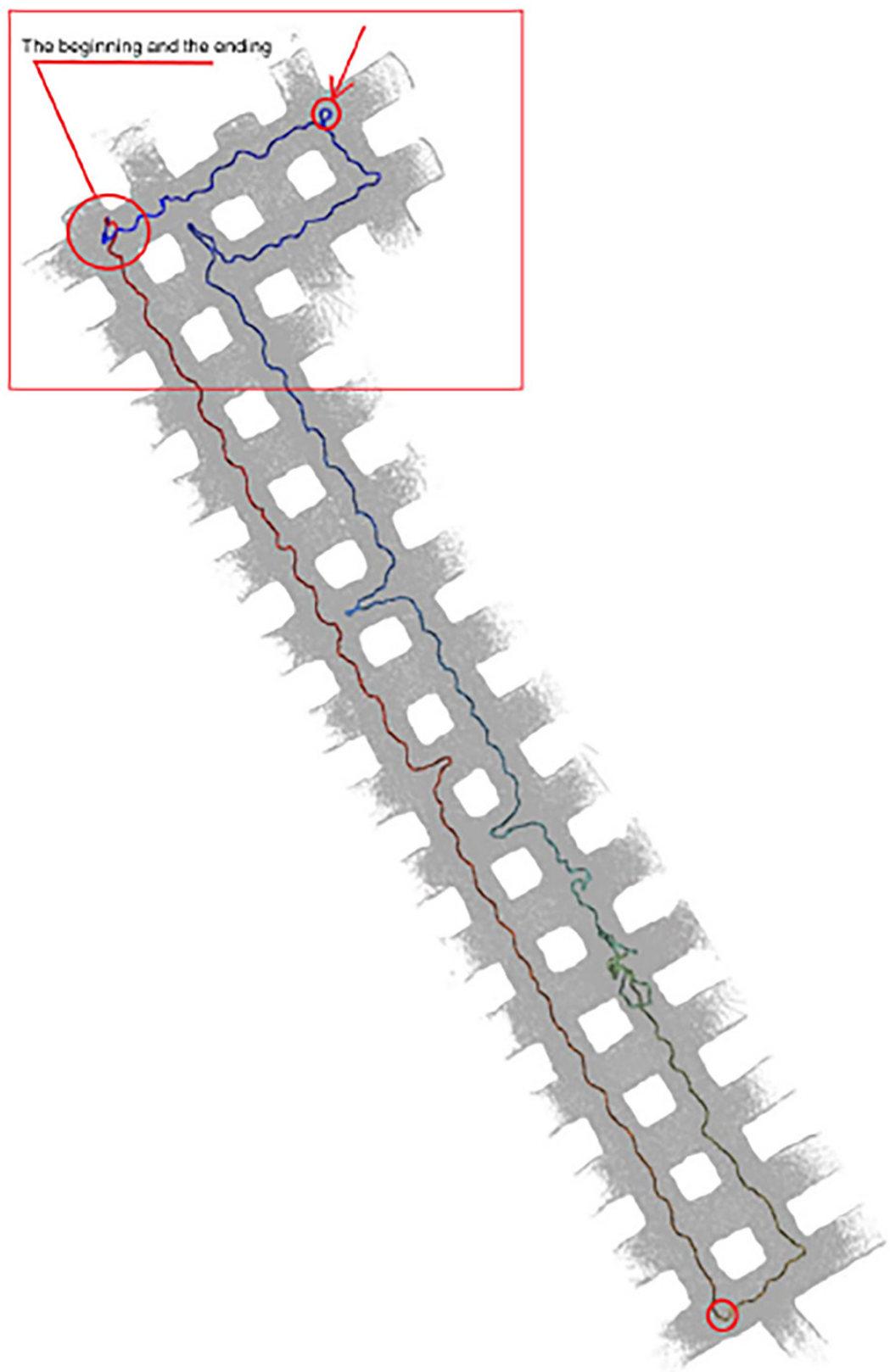

Fig. 6. A typical handheld MLS survey route (mining block no 1707) in the oil shale mine. Small red circles denote locations of the spherical roof targets. Trajectory colours (from warm tones towards colder ones) indicate the route survey sequences. The arrow points to the small circle shape trajectory portion at the location of a scanning target. The length of the entire route is about $600 \mathrm{~m}$, taking about 20 walk-minutes. 


\section{Data processing and results}

The TLS and MLS surveyed data need to be taken to off-site (e.g. office) for post-processing. For the TLS data a specially devised software Faro Scene, which uses a cloud-to-cloud principle for registration, merges point clouds of different stations into one final point cloud.

For the handheld MLS a special software GeoSLAM Hub merges the data into a joint point cloud by using the SLAM algorithm, which estimates the trajectory and the surrounding geometry iteratively [20]. The calculations may be time-consuming, though. This depends on the number of TLS stations, whereas for the handheld MLS data the calculation time roughly corresponds to the measuring time. For example, 20 minutes of MLS surveying data collection correspond to 20 minutes of data processing.

The compilation and visualization of the collected data into 2D technical drawings and 3D virtual information models, including cross sections, volume estimates, etc., are highly demanded for a decision-making process in the further design of mining geometry. Over the years different commercial and open source software has become available for visualisation of the laser scanning results. In this study, the further process from point cloud to final results was realized using 3D ReShaper software [21]. The data visualization options of this software are quite advanced, see Figure 7 for an illustration. This software was selected because it enables receiving easily all needed results in one program and also converting the results into CAD-type programs (.dxf format).

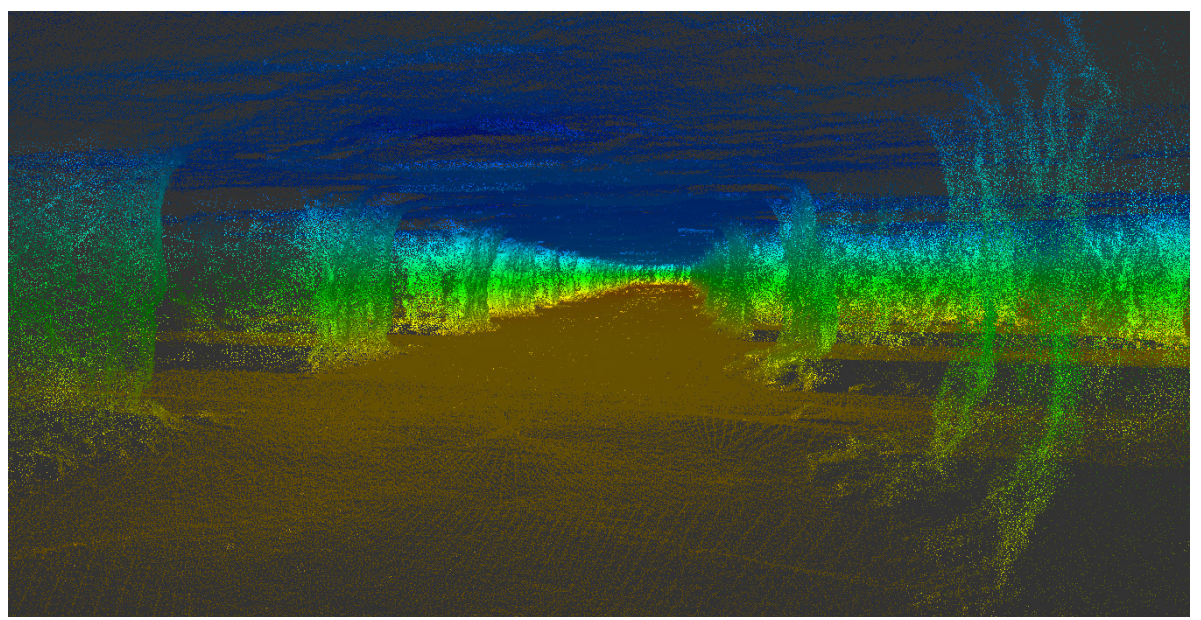

Fig. 7. The georeferenced MLS point cloud of the surveyed mine block. The viewpoint is placed inside the point cloud. The colours denote heights with respect to the mine floor. The coldest colour tone corresponds to the height of $2.8 \mathrm{~m}$ (the mine roof). 


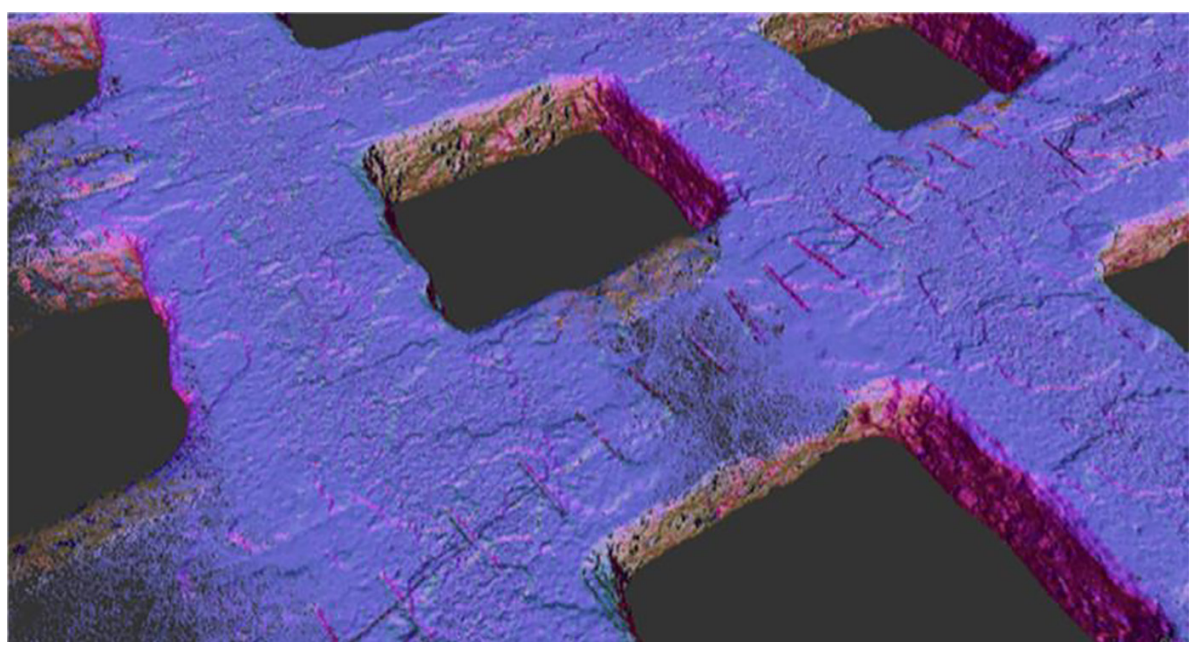

Fig. 8. A point cloud based image of the mine roof with fractured joints and timber structures to support it, a view from above.

The point cloud also enables identification of the relevant auxiliary information, e.g. Figure 8 reveals fractured joints in the mine roof and timber structures to support it.

The above visualisations reflect the results of only one survey. Such surveys need to be performed on a regular basis. According to the present practise the surveyor revisits the same drilling face weekly for extending the survey traverse network, which enables the manual determination of the drilling locations and directions. Usually the extracted volumes and locations of new pillars are surveyed as well. Such a survey can be easily conducted using the handheld MLS. A slight area overlapping with the previously surveyed part is advisable to maintain the consistency of the 3D model. The software incorporates the new survey results into the existing 3D model, facilitating thus a better mine information management.

Advantageously, all the laser scanning point clouds can be stored in one complete database and can always be retrieved and reanalysed at the occurrence of unexpected events, e.g. ground subsidence, pillar failures or roof droppings. Note also that in mine stability calculations the overburden load is often assumed to be permanent, i.e. does not change with time. New heavy loads on the ground, such as deposits of minerals or foundations for the solar panel parks over an extended area, however, increase the rock pressure on the worked-out mining blocks. Hence the adequate surveying data is crucial for reanalyzing the allowability and possible consequences of placing heavy loads on the mine blocks.

The scanning results occupy quite a lot of computer storage space, e.g. one MLS survey may consume about $10 \mathrm{MB}$. This demands more complex data 
processing computers and software than the ones used in the present mine surveying data processing.

\subsection{Discrepancies between TLS and SLAM based point clouds}

The handheld laser scanner point cloud appeared not to be as crisp and clear as the TLS based point clouds, however, their accuracy was sufficient to satisfy the requirements of mine surveys. Apparently, the data scattering is smaller in case of the TLS scanner, whereas the handheld MLS is responsible for larger deviations. Note that the TLS originated data embeds the surfaces by a thin curtain-like point cloud (marking the actual location of the walls, floors and roofs quite crisply), whereas the thickness of the MLS data envelope varies usually between 3 and $5 \mathrm{~cm}$, resembling thus more a thick carpet. The used software approximates the wall surface more or less to the same location, though.

Further comparisons of the TLS and MLS point clouds were conducted using the Best fit registration function of the 3D ReShaper software. This function visualises the results of comparisons between point clouds or 3D surface meshes. Typical discrepancies between the TLS and MLS datasets in the control area (marked in yellow in Fig. 5) remained within $2-5 \mathrm{~cm}$ in horizontal and vertical directions, respectively (Fig. 9).
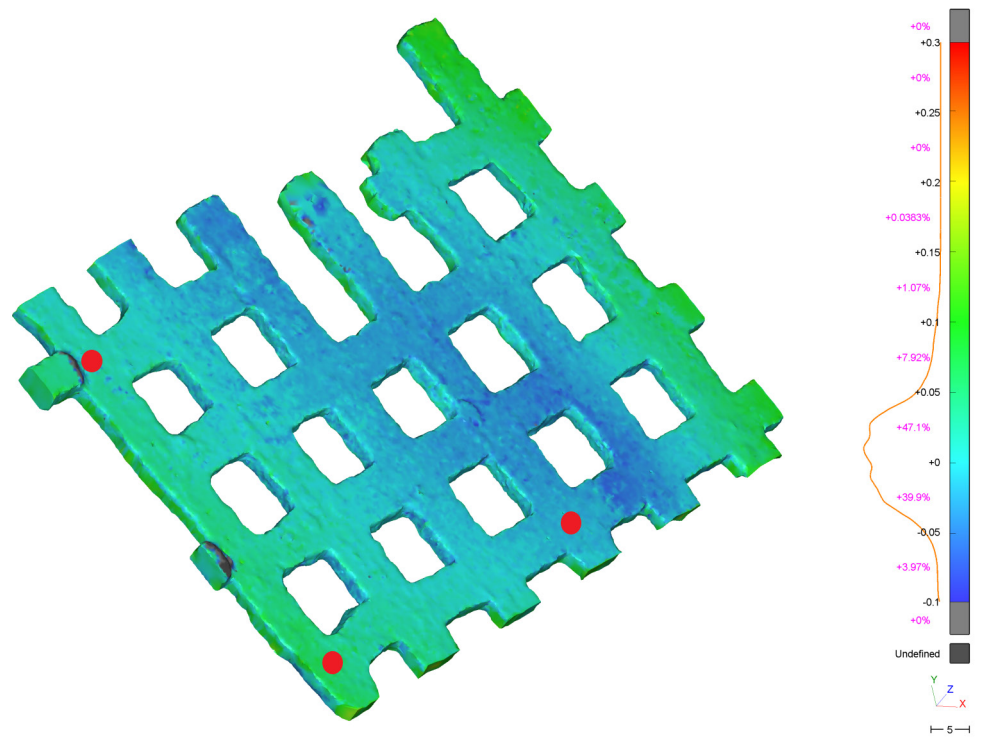

Fig. 9. Discrepancies between the TLS and MLS based results (extracted material) in the control area. The green colour (see the histogram for the discrepancy range and the appearance frequency) denotes areas where the TLS generated surface is higher than that of the MLS. Red circles signify locations of the used spherical targets, the pillars are identifiable by data voids. Unit is metre. 
These discrepancies originate from the application of the handheld MLS technology, whereas the TLS attributed results are assumed to precisely reflect the actual geometry of the mining block. The edges of the control area appear to be more distorted. This may be due to the limited distribution of targets (in Fig. 9 marked as red circles) and georeferencing residuals. Presumably, a better agreement would have been achieved with a larger amount and more even distribution of spherical targets. However, most discrepancies (over 85\%) remain within $\pm 5 \mathrm{~cm}$, thus the handheld MLS is acceptable for mine surveys.

\subsection{Comparison of surveyed areas and locations of pillars}

The room and pillar mining method retains pillars to support the mine roof, hence an accurate determination of their volumes and locations is crucial. The lengths of the pillar sides are conventionally measured by the mine surveyors at the height of the limestone interbed (cf Fig. 10, denoted as C/D in literature) with Disto-type handheld laser distance meters. These measures will then serve for volume computations by a simplified length*width*height formula.

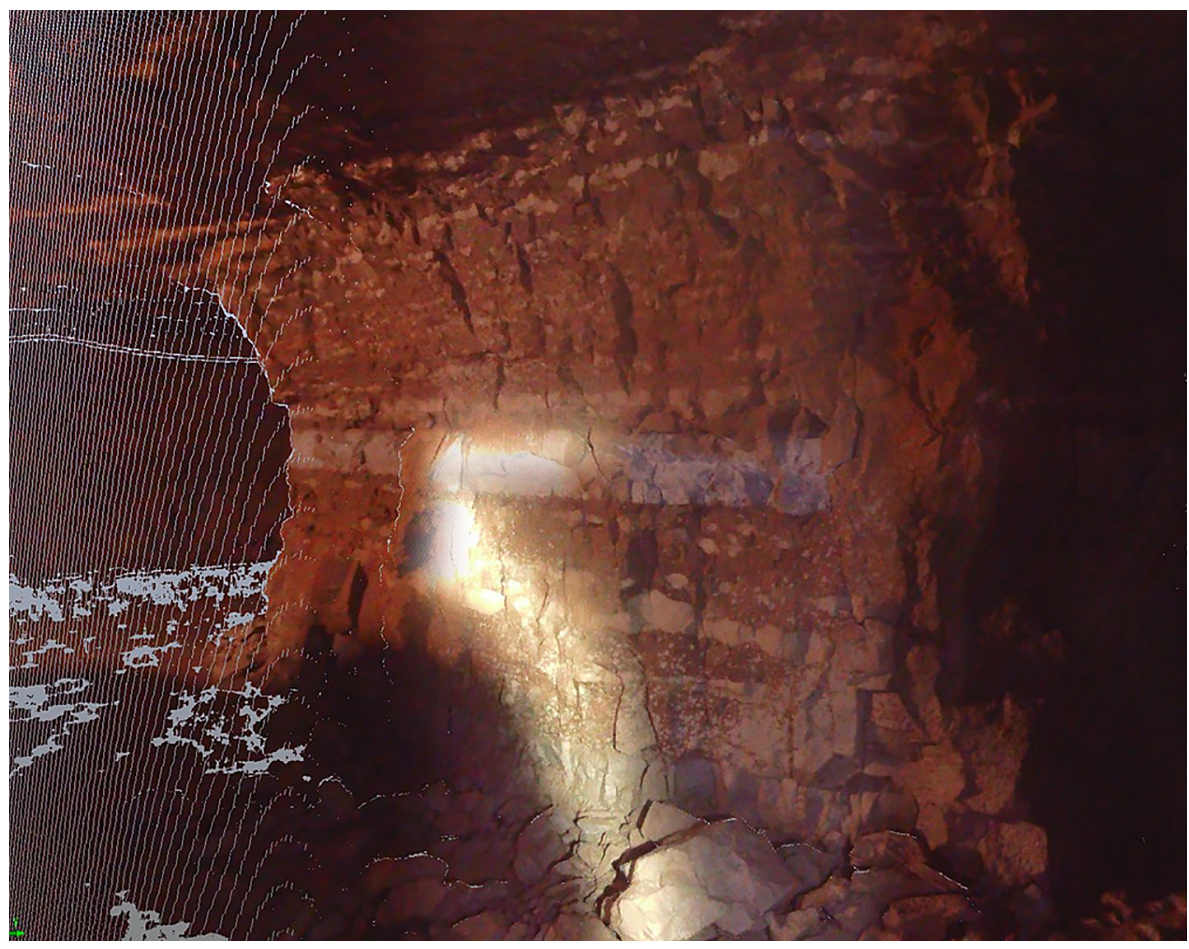

Fig. 10. A high-resolution TLS point cloud of a pillar, the limestone interbed can be identified by a centrally (at the height of $1.6 \mathrm{~m}$ from the mine floor) located bright layer. 
The corners of the pillars are distance-measured with respect to the roof-mounted points of the survey network. The results are handwritten in the field books. The final shape and location of pillars are drawn (for a sample see Fig. 11) manually in the CAD-based program.

The laser scanning software generates a unified point cloud. The true coloured TLS point cloud (cf Fig. 10) allows also distinguishing between different seams in the oil shale bed. The software tools enable measurement of their thickness, the results can be used for improving the run-of-mine quality estimates. To assess the precision of the mine surveyor's area measurements, the horizontal cross sections of both scanning point clouds were established at the height of the limestone interbed $(1.6 \mathrm{~m})$. The corresponding areas of the pillars were calculated and the results compared with data obtained by conventional surveying methods, see Figure 11.

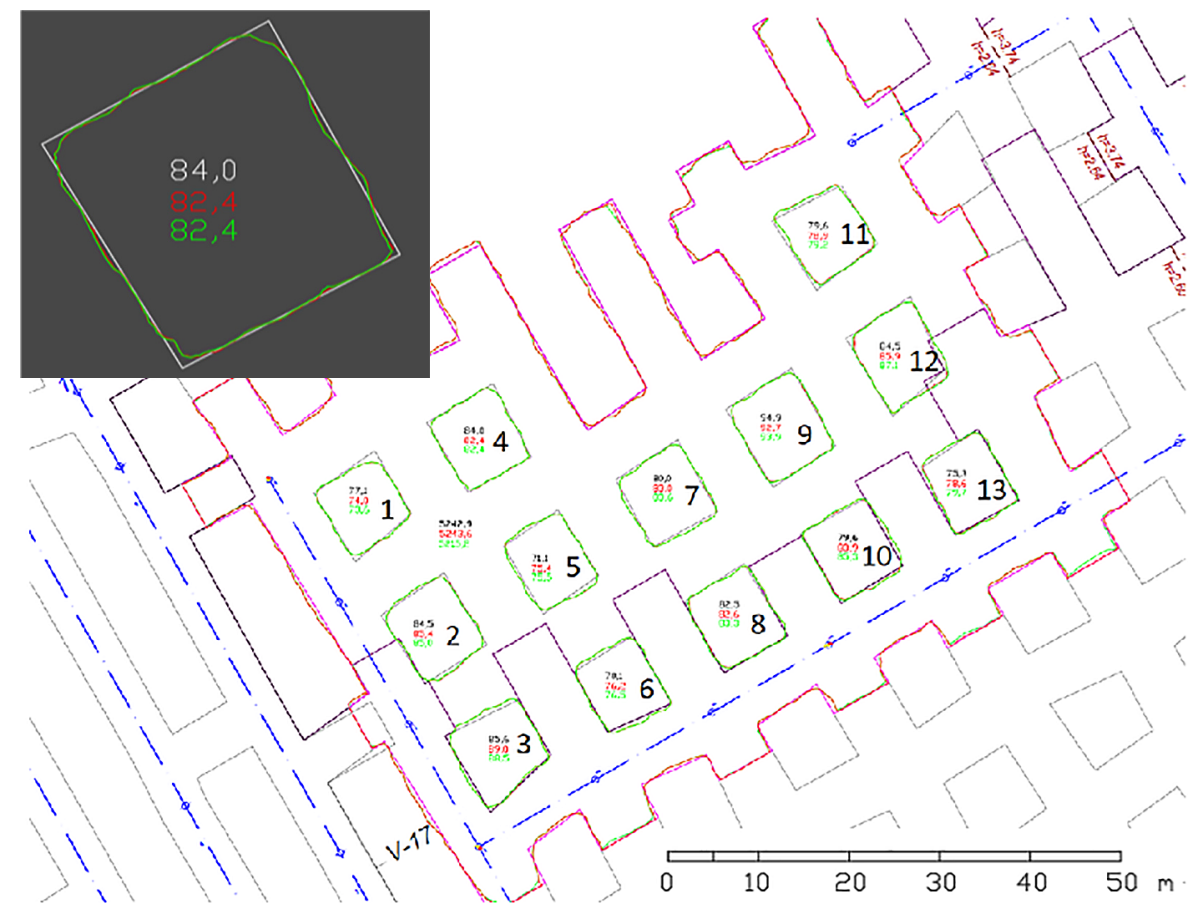

Fig. 11. Shapes and locations of pillars (numbered 1-13) in mining block no 1214 . The black background inset contains cross-section area estimates for pillar no 4, see also Table 2. The red contour and font denote the TLS attributed (reference) results, the green and grey contours/fonts indicate the handheld MLS and Disto related results, respectively. Units are in $\mathrm{m}^{2}$. The underlying map is compiled by the mine surveyors of the Estonia oil shale mine. Note the straight-line drawn pillar shapes, whereas in reality the pillars slightly resemble hourglass shapes, cf Figure 10. 
The cross-section areas and locations of 13 pillars determined in different surveys in the control area (cf Fig. 4) are very similar. This evidences the good quality of the mining network coordinates and successful georeferencing of the laser scanning results. The TLS and MLS based pillar contours agree within centimetres. The Disto measurements based shapes are simplified, but still in good agreement with the actual shape of the pillars, cf Figure 11. The cross-section areas of pillars are numerically compared in Table 2.

Table 2. Cross-section areas of pillars in mining block no 1214 obtained by different measurement techniques

\begin{tabular}{|c|c|c|c|}
\hline Quantity and unit & $\begin{array}{l}\text { TLS based cross- } \\
\text { section area estimate } \\
\text { (reference data), } \mathrm{m}^{2}\end{array}$ & $\begin{array}{c}\text { Handheld MLS } \\
\text { based estimate, } \\
\mathrm{m}^{2}\end{array}$ & $\begin{array}{c}\text { Disto survey } \\
\text { based estimate, } \\
\mathrm{m}^{2}\end{array}$ \\
\hline Pillar 1, cf Fig. 11 & 74.0 & 73.6 & 77.1 \\
\hline 2 & 85.4 & 85.0 & 84.5 \\
\hline 3 & 89.0 & 88.5 & 85.6 \\
\hline 4 & 82.4 & 82.4 & 84.0 \\
\hline 5 & 75.4 & 75.5 & 71.1 \\
\hline 6 & 76.2 & 76.5 & 70.1 \\
\hline 7 & 83.0 & 83.6 & 80.0 \\
\hline 8 & 82.6 & 83.3 & 82.5 \\
\hline 9 & 92.7 & 93.9 & 94.9 \\
\hline 10 & 83.9 & 85.3 & 79.6 \\
\hline 11 & 78.9 & 79.2 & 79.6 \\
\hline 12 & 85.9 & 87.1 & 84.5 \\
\hline Pillar 13 & 78.6 & 79.7 & 75.3 \\
\hline Total area, $\mathrm{m}^{2}$ & 1068.0 & 1073.6 & 1048.8 \\
\hline $\begin{array}{l}\text { Difference from reference } \\
\quad \text { (TLS) data, } \mathrm{m}^{2}\end{array}$ & - & -5.6 & +19.2 \\
\hline$\%$ of TLS data & - & -0.5 & +1.8 \\
\hline $\begin{array}{l}\text { Difference from handheld } \\
\text { MLS data, } \mathrm{m}^{2}\end{array}$ & - & - & +24.8 \\
\hline$\%$ of MLS data & - & - & +2.3 \\
\hline
\end{tabular}


Since the TLS based point cloud is crispier than that of the handheld MLS, then this allows us to assume that the former is more accurate and reliable. Therefore the TLS based results represent the reference data for verification of the handheld MLS and Disto-type measurements.

It appears that the individual discrepancies between the TLS and MLS results are random and mostly $<1 \mathrm{~m}^{2}$. Such small differences may be due to a possible shift between the TLS and MLS cross sections. Conversely, the majority of the Disto measurements yield systematically smaller pillar cross-section areas when compared to the reference data, cf Table 2.

Since the total discrepancies between the TLS and handheld MLS are less than $0.5 \%$, then the latter can also be used for a further verification of conventional Disto type measurements. The Disto-measured total area of pillars appeared to be $1.8 \%$ smaller than the reality. In other words, in this particular mining block no 1214 the conventionally calculated volume of extracted material may exceed the actually extracted volumes.

Interestingly, the case was the opposite for mining block no 1707 which was Disto-measured by a different surveyor. There the Disto based measurements yielded a $1-8 \%$ larger cross-section area for pillars than the MLS scanning. These discrepancies evidence that the manual survey results can be contaminated by the subjectivity of the surveyor's decisions while selecting the pillar survey points. Conversely, the scanning results provide an objective outcome due to evenly and densely spaced points within the point cloud.

\subsection{Comparison of extracted volumes}

It is important to calculate the volume of the extracted mineral resources as well. The Disto-measured volumes and the handheld MLS values are $0.7 \%$ smaller than the TLS reference data, cf Table 3. A comparison of the handheld MLS results with the Disto survey data shows an insignificant difference, $0.04 \%$ only. In mining block no 1707 (with very similar surveying conditions) this difference is $0.2 \%$ (Table 3 ).

The discrepancies between TLS, handheld MLS and Disto data are slight and more than 10 times smaller than the discrepancy values allowed by Estonian mining regulations today $[15,22]$. Hence all the tested methods provide satisfactory results. However, the handheld MLS possesses the following advantages: (i) decrease in data acquisition costs and shortened fieldwork time; (ii) fast and accurate modelling of 3D spaces; (iii) reduced need for a possible resurvey; (iv) enhanced surveyor safety (e.g. hazardous objects); (v) better information management. 
Table 3. Comparison of extracted volumes in mining blocks no 1214 and no 1707

\begin{tabular}{|c|c|c|c|}
\hline Quantity and unit & $\begin{array}{l}\text { TLS based } \\
\text { estimate, } \mathrm{m}^{2}\end{array}$ & $\begin{array}{c}\text { Handheld MLS } \\
\text { based estimate, } \mathrm{m}^{2}\end{array}$ & $\begin{array}{l}\text { Disto survey based } \\
\text { estimate, } \mathrm{m}^{2}\end{array}$ \\
\hline \multicolumn{4}{|c|}{ Mining block no 1214} \\
\hline $\begin{array}{l}\text { Total volume of the } \\
\text { control area, } \mathrm{m}^{3}\end{array}$ & 11067.7 & 10984.2 & 10988.5 \\
\hline $\begin{array}{l}\text { Difference from TLS } \\
\text { data, } \mathrm{m}^{3}\end{array}$ & & 83.6 & 79.2 \\
\hline$\%$ of TLS data & & 0.7 & 0.7 \\
\hline $\begin{array}{l}\text { Difference from handheld } \\
\text { MLS data, } \mathrm{m}^{3}\end{array}$ & & & 4.4 \\
\hline$\%$ of MLS data & & & 0.04 \\
\hline \multicolumn{4}{|c|}{ Mining block no 1707} \\
\hline Total volume, $\mathrm{m}^{3}$ & & 29187.6 & 29140.5 \\
\hline $\begin{array}{l}\text { Difference from MLS } \\
\text { data, } \mathrm{m}^{3}\end{array}$ & & & 47.1 \\
\hline$\%$ of MLS data & & & 0.2 \\
\hline
\end{tabular}

\section{Conclusions}

Modern digital surveying technology is often underexploited in mining industry. In this study, new innovative laser scanning technologies were tested in oil shale mining conditions. Satisfying results were obtained by using handheld mobile laser scanners, which have become a very efficient surveying tool for solving outdoor engineering tasks due to contactless measurements, reasonable measuring distances and very fast data acquisition rates. The SLAM algorithm used in the mobile and lightweight scanners enable survey teams to map and monitor sites quickly on foot, at a walking speed.

The test results obtained were compared with those of the currently used surveying methods. The study shows that handheld MLS is well suited for mine surveying as it is accurate, fast and quite easy to handle. Only one surveyor is needed to operate the modern handheld MLS device after a minimal training. 
The semi-automatic data acquisition minimizes human made subjective errors. The further automatization of the mine surveying workflow can be achieved by upgrading the mining/drilling technology currently used in oil shale mines.

Handheld laser scanners can improve the surveying methods in mines and modernize mining surveying in Estonia and, under similar conditions, elsewhere. Importantly, a precise estimation of the mining losses, locations of the pillars and extracted volumes by a modern digital surveying technology is very essential for further increasing the efficiency of oil shale mining.

\section{Acknowledgements}

This paper is based on the experimental study LEP18086 "Applied research on improving the effectiveness of mine surveyor works using remote sensing methods" carried out in cooperation with the Department of Geology and the Department of Civil Engineering and Architecture, Tallinn University of Technology. The research is partly supported by the Estonian Research Council Grant PRG330. The Manager of the private surveying company Hades Geodeesia OÜ, Mr T. Hion, is acknowledged for providing both the laser scanners. Mr. V. Veeleid is thanked for instructing and advising during the fieldwork and data processing. The managerial and engineering personnel (Mrs. V. Kaljuste, Mr. R. Roots, Mr. A. Viil) of the state enterprises Eesti Energia and Enefit Kaevandused are thanked for giving an opportunity to improve surveying methods in the Estonia underground mine. Mr. S. Varbla and Dr. K. Julge of the Department of Civil Engineering and Architecture, Tallinn University of Technology are thanked for assisting in the research work. Prof. A. Siirde and an anonymous reviewer are acknowledged for useful suggestions.

\section{REFERENCES}

1. Sobak, M., Ellmann, A., Mill, T. Terrestrial laser scanning assessment of generalization errors in conventional topographic surveys. Geodesy Cartogr., 2015, 41(1), 15-24.

2. Wunderlich, T. A. Terrestrial laser scanners - an important step towards construction information. FIG Working Week, Paris, France, April 13-17, 2003, $1-11$.

3. Murphy, M., McGovern, E., Pavia, S. Historic building information modelling - adding intelligence to laser and image based surveys of European classical architecture. ISPRS J. Photogramm. Remote Sens., 2013, 76, 89-102.

4. Varbla, S., Puust, R., Ellmann, A. Accuracy assessment of RTK-GNSS equipped UAV conducted as-built surveys for construction site modelling. Surv. Rev., 2020. DOI: $10.1080 / 00396265.2020 .1830544$ 
5. Mill, T., Ellmann, A. Assessment of along-normal uncertainties for application to terrestrial laser scanning surveys of engineering structures. Surv. Rev., 2019, 51(364), 1-16. DOI: 10.1080/00396265.2017.1361565

6. Mill, T., Ellmann, A., Aavik, A., Horemuz, M., Sillamäe, S. Determining ranges and spatial distribution of road frost heave by terrestrial laser scanning. Balt. J. Road Bridge Eng., 2014, 9(3), 225-234. DOI: 10.3846/bjrbe.2014.28

7. Julge, K., Vajakas, T., Ellmann, A. Performance analysis of a compact and lowcost mapping-grade mobile laser scanning system. J. Appl. Remote Sens., 2017, 11(4), 044003. DOI: 10.1117/1.JRS.11.044003

8. Lõhmus, H., Ellmann, A., Märdla, S., Idnurm, S. Terrestrial laser scanning for the monitoring of bridge load tests - two case studies. Surv. Rev., 2017, 50(360), 270-284. DOI: 10.1080/00396265.2016.1266117

9. Julge, K., Ellmann, A., Köök, R. Unmanned aerial vehicle surveying for monitoring road construction earthworks. Balt. J. Road Bridge Eng., 2019, 14(1), 1-17. DOI: 10.7250/bjrbe.2019-14.430

10. Zlot, R., Bosse, M. Efficient large-scale 3D mobile mapping and surface reconstruction of an underground mine. Field and Service Robotics, Results of the 8th International Conference, Tohoku University/Matsushima, Japan, July 16-19, 2012.

11. Eesti Energia AS. Applied Research on Improving Effectiveness of Mine-Surveyor Works Using Remote Sensing Methods (Procurement \#195308). Tallinn, 2018 (in Estonian). https://riigihanked.riik.ee/rhr-web/\#/procurement/722774/generalinfo (accessed 20.07.2020).

12. Koitmets, K., Reinsalu, E., Valgma, I. Precision of oil shale energy rating and oil shale resources. Oil Shale, 2003, 20(1), 15-24.

13. Toomik, P. Geological conditions and technological possibilities of oil shale mining in Narva opencast. MSc Thesis, Tallinn University of Technology, Tallinn, 2015 (in Estonian). https://digikogu.taltech.ee/et/Item/ebfb226d-3610400b-a762-21a6c05fb80b (accessed 06.12.2020).

14. Credo Dialogue. 2014-2020. https://credo-dialogue.ru/ (accessed 06.12.2020).

15. Specified requirements for mining surveys. $R T I, 18.08 .2020,4$ (in Estonian). https://www.riigiteataja.ee/akt/107052019005 (accessed 21.08.2020).

16. Zlot, R., Bosse, M. Efficient large-scale three-dimensional mobile mapping for underground mines. J. Field Robot., 2014, 31(5), 758-779.

17. ZEB-REVO User Manual v3.0.0 GeoSLAM Ltd, 2017. http://download. geoslam.com/docs/zeb-revo/ZEB-REVO\%20User\%20Guide\%20V3.0.0.pdf (accessed 20.07.2020).

18. Faro Product Info. Faro Laser Scanner Focus ${ }^{3 D}$ X330 HDR. Tech Sheet, 2016. https://faro.app.box.com/s/kaeo5jwguxe1 tacvzea7berpzm0phofp/ file/441644006961 (accessed 20.07.2020).

19. Malberg, K. Determining the Shape and Volume of Enclosed Spaces and Underground Mines by Mobile Laser Scanning. MSc Thesis, Tallinn University of Technology, Tallinn, 2019 (in Estonian). https://digi.lib.ttu.ee/i/?12484\& (accessed 29.07.2019). 
20. Durrant-Whyte, H., Bailey, T. Simultaneous localization and mapping (SLAM): part I. The essential algorithms. IEEE Robot. Autom. Mag., 2006, 13(2), 99-110.

21. 3DReshaper. Technodigit part of Hexagon, 2020. https://www.3dreshaper.com/ en/software-en/ (accessed 06.12.2020).

22. The Earth's Crust Act, RT I, 21.12.2019, 11. (In Estonian). https://www.riigiteataja.ee/ akt/MaaPS (accessed 06.12.2020). 